\title{
Analysis of the EBR-II SHRT-45R Unprotected Loss of Flow Experiment with ERANOS and RELAP
}

\author{
W. F. G. van Rooijen and H. Mochizuki \\ Research Institute of Nuclear Engineering, University of Fukui, Kannawa-cho 1-2-4, Tsuruga-shi, Fukui-ken T914-0055, Japan \\ Correspondence should be addressed to W. F. G. van Rooijen; rooijen@u-fukui.ac.jp
}

Received 6 February 2015; Accepted 18 August 2015

Academic Editor: Andreas Pautz

Copyright (c) 2015 W. F. G. van Rooijen and H. Mochizuki. This is an open access article distributed under the Creative Commons Attribution License, which permits unrestricted use, distribution, and reproduction in any medium, provided the original work is properly cited.

\begin{abstract}
This paper presents the results of the analysis of the Unprotected Loss of Flow (ULOF) experiment SHRT-45R performed in the EBR-II fast reactor. These experiments are being analyzed in the scope of a benchmark exercise coordinated by the IAEA. The SHRT$45 \mathrm{R}$ benchmark contains a neutronic and a thermal-hydraulic part and results are presented for both. Neutronic calculations are performed with the ERANOS2.0 code in combination with various sets of nuclear data. The thermal-hydraulic evaluation is done with RELAP5-3D. The results are that the major neutronic parameters are well predicted with error margins on the order of $1 \%$. The thermal-hydraulic results are less favourable: a consistent overestimation of the outlet temperature occurs in combination with erroneous flow distribution. Observed differences with measured data cannot be explained easily. The work presented in this paper was undertaken to investigate and validate the effectiveness of the calculational tools and data that are commonly used in our lab for the design and analysis of liquid metal cooled fast reactors.
\end{abstract}

\section{Introduction}

The Experimental Breeder Reactor II (EBR-II) was a small (60 MWth) fast breeder reactor operated by the Argonne National Laboratory (ANL) from 1964 to 1994. The reactor used liquid sodium as a coolant and metallic fuel and had a large amount of measurement equipment in the primary system. In 1984 a series of experiments was performed aimed at testing inherent safety. Two of these experiments (SHRT17 and SHRT-45R) have been made available by the ANL as a benchmark exercise. This benchmark exercise is coordinated by the IAEA.

In this paper our analysis of the SHRT-45R experiment is reported. The SHRT-45R experiment is an Unprotected Loss of Flow (ULOF) from full power. Since EBR-II has favourable natural feedback features the reactor transitions automatically into a safe, low power state during the ULOF transient. The SHRT-45R benchmark has two parts, namely, a neutronic benchmark and a thermal-hydraulic (TH) benchmark. The objective is that participants determine feedback coefficients from the neutronic benchmark and use these coefficients in the TH benchmark.
We have previously reported on the results of the SHRT$45 \mathrm{R}$ TH benchmark [1]. In that work, it was necessary to "tune" the feedback parameters because of the limitations of the $\mathrm{TH}$ modeling code (NETFLOW ++ ). In this paper, we will present a detailed overview of the neutronics benchmark and the result from an analysis with the RELAP5-3D v4.1.3 code [2], which allows a more detailed treatment of feedback effects. The main objectives of the work were the following: (a) support the validation status of our custom-built neutron cross section libraries, (b) validate the overall setup of our fast reactor neutronics analysis software, and (c) assess the performance of RELAP (a "traditional" circuit code) in analyzing a small, liquid metal cooled fast reactor. As far as validation goes, it is noted that the EBR-II core is different from "conventional" fast reactors (metallic fuel versus oxide, highly enriched uranium versus MOx). In particular for RELAP5$3 \mathrm{D}$ the validation status for metal cooled systems seems relatively sparse and therefore the present work provided new validation information.

The paper is organized as follows: in Sections 2 and 3 the neutronic benchmark and its results are discussed. 
In Sections 4 and 5 the thermal-hydraulic benchmark and its results are discussed. Finally, conclusions are presented.

\section{Neutronic Benchmark}

The EBR-II benchmark is described in two documents, one of which details the thermal-hydraulic part (ANL-ARC226 [3]), while the other document describes the neutronic benchmark (ANL-ARC-228 [4]). The neutronic benchmark consists basically of a detailed description of the EBR-II core at the time of the SHRT-45R experiment. Material compositions are prescribed for each individual assembly in the core. The objective is to calculate the major neutronic parameters of the EBR-II reactor, that is, multiplication factor, Doppler coefficient, and various feedback effects, such as radial and axial thermal expansion and control rod drive expansion. Calculations are performed with the well-established fast reactor analysis code system ERANOS 2.0 [5]. We prepared three sets of neutron cross section libraries and covariance data for ERANOS 2.0, based on JENDL-4.0 [6], JEFF-3.1.2 [7], and ENDF/B-VII.1 [8], respectively.

The core map for the SHRT-45R experiment is completely described in the benchmark specification [3]. The core comprises a total of 14 full rings of hexagonal subassemblies and 2 partially filled rings (15 and 16). In ERANOS it is not possible to use a hexagonal geometry with "empty" positions; therefore, assemblies are added to the open positions in ring 15 , and ring 16 is deleted from the model. The resulting core layout is illustrated in Figure 1, and in Figure 2 an overview of the driver core is given, rings 1 to 7 .

The benchmark specifies several assembly types, which are color-coded in Figures 1 and 2. For each assembly type, the benchmark provides a description of the geometry in axial direction. For assemblies containing fuel, the fuel region is divided into three axial zones and compositions are given for each zone. Since there are 425 assemblies containing fuel (including the radial blanket assemblies), there are a total of 1275 different compositions for the fuel and blanket assemblies and another 24 materials for axial shields, fission gas plenum, and so forth. The shear number of different compositions makes it unpractical to perform individual cell calculations for each fueled zone. Therefore, cell calculations are performed as follows:

(i) Detailed cell calculations are done for four representative assembly types: half-worth driver (position 01A01, 91-pin hexagonal bundle with 45 fueled pins and 46 stainless steel pins); full-worth driver (04A01, 91-pin hexagonal bundle); control/safety assembly (05A01, 61-pin hexagonal bundle in a guide thimble); and blanket assembly (12A01, 19-pin hexagonal bundle). A cross section of these cells is given in Figure 3. Cell calculations are performed for the three axial layers defined in each of these assemblies. Cell calculations are performed in 2D; for the half-worth driver, the exact pattern of stainless steel rods and fuel rods is taken into account.

(ii) For subcritical cells, the ECCO code has a special treatment: the cell is treated as a subcritical cell with a neutron source. In this case, the user defines a material region (calculation cell) from which to take a representative neutron spectrum. The neutron source for the subcritical cell is calculated from the representative neutron spectrum as follows:

$$
S=D_{\text {source }} \phi_{\text {source }} \text {. }
$$

To take into account leakage effects (correction through $\Sigma_{t}+D B^{2}$ ), the user also has to define a geometrical buckling for the subcritical cells; the recommended value of the buckling is

$$
B^{2}=\frac{5}{8}\left(\frac{\pi}{L_{\text {typ }}}\right)^{2},
$$

where $L_{\text {typ }}$ is a typical dimension for the subcritical region.

(iii) Nonfissile materials are treated as infinite homogeneous (0D) materials. These materials include, for example, the stainless steel reflector assemblies; the dummy assemblies in the core; the absorber sections of the control rods; and the material regions below and above the core, including the gas plenum, bond section, and shield section.

(iv) The order of calculation is determined by the need to have representative neutron spectra to serve as the source term for the subcritical cells (which include the nonmultiplying materials). Thus, first the full-worth driver, half-worth driver, and the fueled sections of the control rods are treated. The resulting neutron spectra are used to calculate the nonfissile cells. Finally, since the blanket region is outside of the stainless steel reflector, the neutron spectrum of the reflector region is used in the treatment of the blanket cells.

(v) The homogenization of control rods requires special treatment. In ERANOS, special treatment is available for the control rods, where the effective homogenized cross sections are calculated based on the reactivity equivalence method [5].

The core contains assemblies with many different compositions, whereas only a small number of cell calculations are performed. For each material region, the microscopic cross sections from the cell calculation are used with the number densities of the isotopes according to the benchmark description; the corresponding macroscopic cross sections are calculated. This is done for each of the fuel and blanket assemblies. It should be noted that this approach implies that, for each type of assembly, only three sets of microscopic cross sections are available (one set for each axial region defined in the benchmark). This approach is deemed to be acceptable because the difference in self-shielding is small within each group (type) of core assemblies, as the compositions do not vary too much between the assemblies.

The core model maintains the axial divisions of the assemblies as much as possible. When the full-core geometry is made, the "unified" axial mesh may have meshes with very 


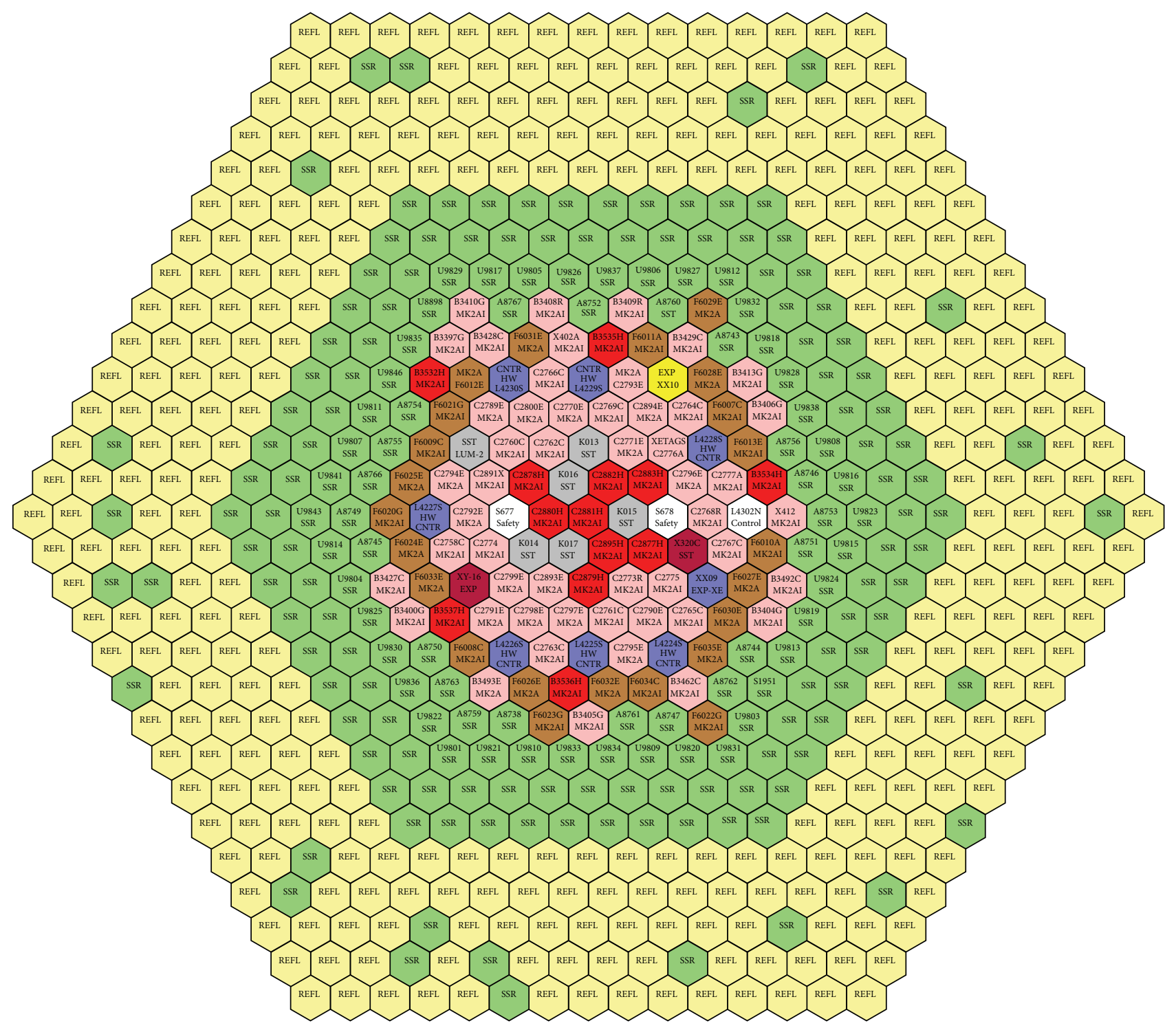

$\begin{array}{ll}\text { Color coding: } & \bigcirc \text { Safety SA } \\ \text { Driver SA } & \text { Reflector SA } \\ \text { Half-worth driver SA } & \text { Dummy SA } \\ \text { High-flow driver SA } & \text { Experimental SA } \\ \text { Blanket SA } & \text { Instrumented SA }\end{array}$

FIGURE 1: EBR-II reactor for the SHRT-45R neutronics benchmark.

small values of $\Delta z$ (e.g., due to partially inserted control rods or slight variations in the axial shield design). For reasons of calculation time and numerical stability such small meshes are to be avoided. Therefore, in some cases the axial extent of material regions was changed slightly, making sure that the total mass of all materials was correctly conserved. One might say that the "unified" mesh is a bit "thinned out" to avoid such small mesh sizes. For the reference core calculations, the axial mesh has 46 intervals (for "critical control rod insertion") with $\Delta z$ ranging from $2 \mathrm{~cm}$ to $5 \mathrm{~cm}$.

A note should be made about the boundary conditions for the core calculation. In ERANOS, one can choose the boundary conditions of the core model from the following formula:

$$
J-\mu \phi=0, \quad 0 \leq \mu<\infty,
$$




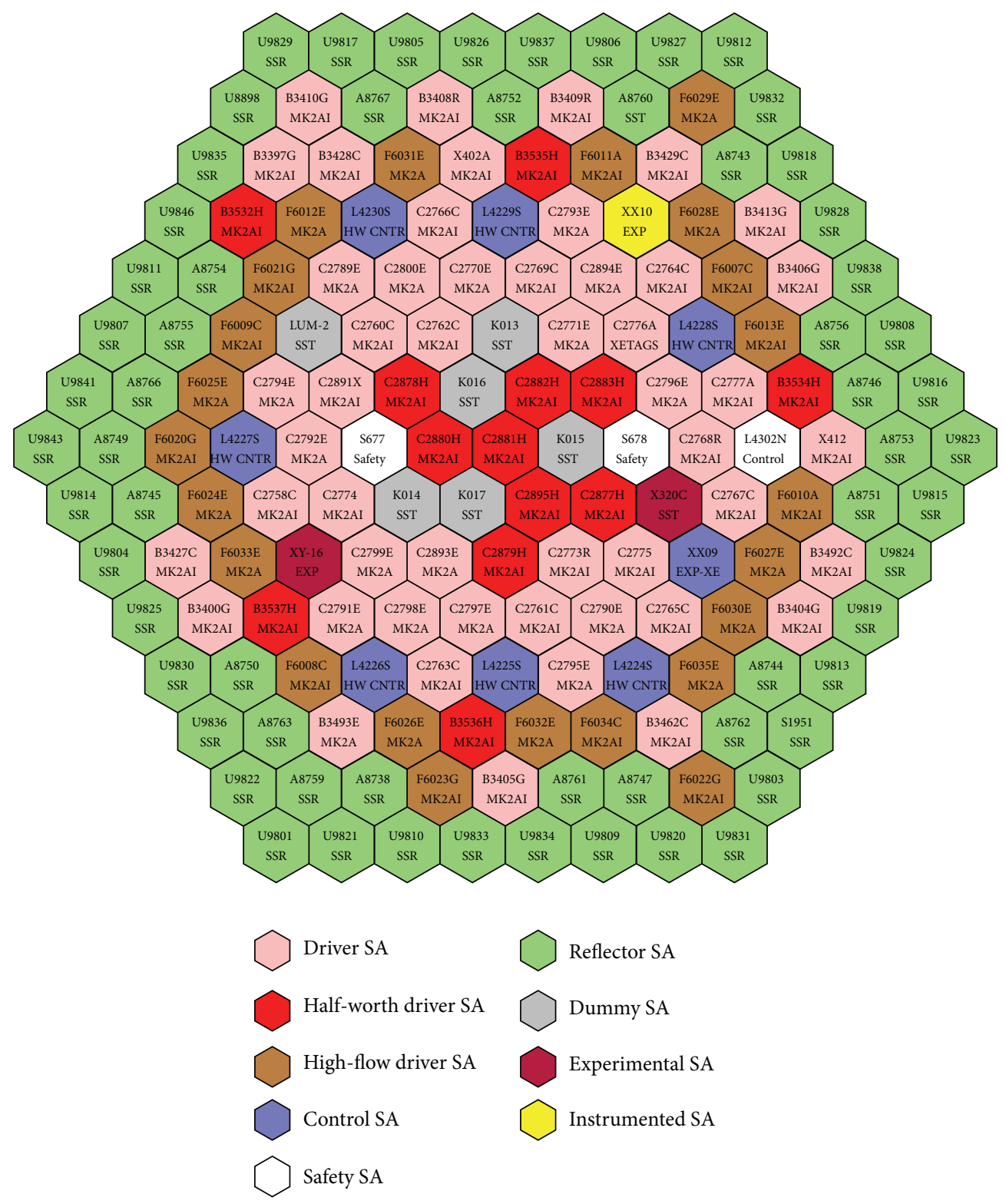

FIGURE 2: EBR-II reactor core for the SHRT-45R neutronics benchmark.

where $J$ is the current on the boundary and $\phi$ is the flux. Setting $\mu=0$ gives $J=0$, that is, reflective boundary condition, $\mu=1 / 2.13 \approx 0.46948$ gives the vacuum boundary condition, and $\lim _{\mu \rightarrow \infty}$ corresponds to $\phi=0$ on the boundary. In the present work, the boundary condition is not exactly a vacuum boundary condition, nor is it a reflective boundary condition. Finally, $\mu=0.1$ was used to be in between a vacuum boundary condition and reflective boundary condition. Since the EBRII core is surrounded by a large amount of sodium, the boundary condition is expected to be closer to reflection than to vacuum. A sensitivity study was carried out to estimate the influence of $\mu$ on the multiplication factor and power distribution, and it was found that these quantities were hardly influenced by the value of $\mu$.

ERANOS has several options for core calculations. In the present work, we have chosen to use the following: (i) First is the nodal transport code based on $P_{N}$ calculations (TGV-VARIANT). This code uses Hex-Z geometry. A scoping study was done to determine the optimal settings in TGV-VARIANT with respect to accuracy and calculational expense.

(ii) To obtain forward and adjoint fluxes for perturbation and sensitivity analysis, finite difference diffusion theory calculations were also done. A limitation in ERANOS 2.0 precludes the use of nodal fluxes for such calculations.

Unlike the finite difference method, the nodal method does not suffer from the effect of a finite mesh size, and therefore TGV transport should be considered the best possible solution. All core calculations were done with 33 energy groups. 


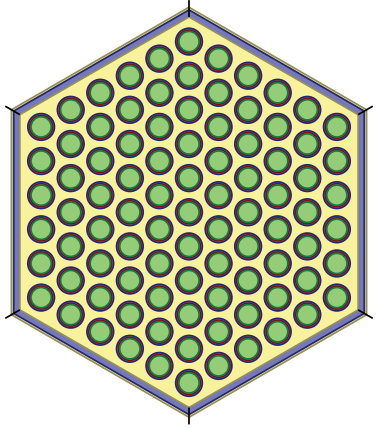

(a) Full-worth driver

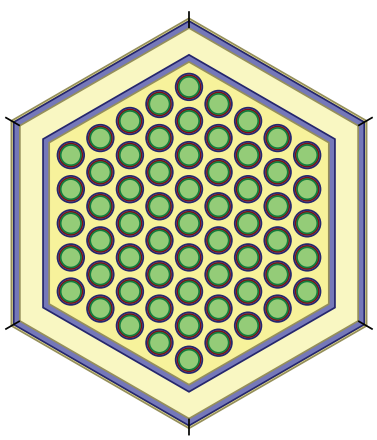

(c) Control rod

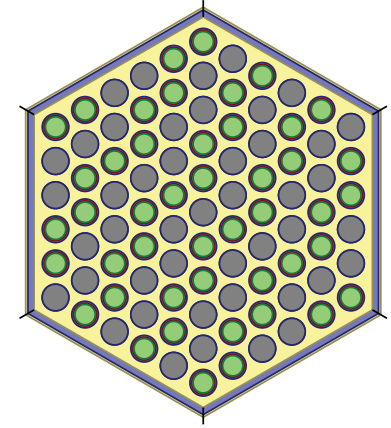

(b) Half-worth driver (45 fuel pins and 46 steel pins)

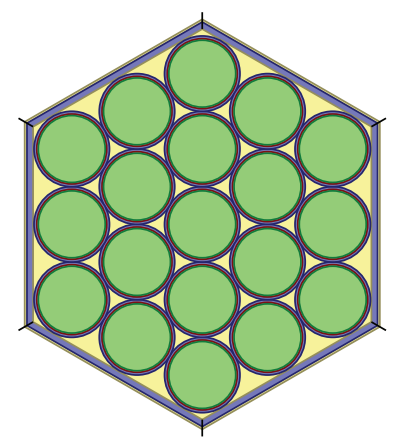

(d) Blanket SA

FIgURE 3: Cross section for the 2D cell calculations in ECCO.

\section{Results and Discussion of the Neutronics Benchmark}

Major results are given in Table 1. Uncertainties in this table are uncertainties due to cross sections only. These uncertainties were calculated with the conventional methods for the estimation of cross section uncertainties: perturbation theory is used to estimate the sensitivity coefficients of the calculated parameters, and the sensitivity coefficients are folded with the cross section covariance data ("cross section error") to give the error margin of the calculated parameter. The standard routines of ERANOS were used for this purpose. Figure 4 contains the control rod worth curve (all control rods move simultaneously). At this stage, the uncertainty of the control rod worth has not been calculated. In Figure 5 the power distribution obtained with JENDL-4.0 is given. Results for JEFF-3.1.2 and ENDF/B-VII.1 are similar.

Figure 5 requires more explanations because the error (difference between our calculations and benchmark specification) is very high in some cases (up to 66\%). Two issues are pointed out:

(i) The benchmark values are not measured values, but predicted values, calculated with the core management software of EBR-II at the time of the experiments. Error margins on the predicted values are not given in the benchmark materials.

(ii) The largest errors occur generally in assemblies with the lowest power, and these are generally nonfueled
TABLE 1: Main results of the EBR-II SHRT-45R neutronics benchmark.

\begin{tabular}{lccc}
\hline Parameter & JENDL-4.0 & JEFF-3.1.2 & ENDF/B-VII.1 \\
\hline Multiplication factor [-] & 0.9923 & 0.9850 & 0.9849 \\
Uncertainty [\%] & 0.44 & 2.1 & 2.1 \\
$\beta_{\text {eff }}[\mathrm{pcm}]$ & 691 & 702 & 708 \\
\hline \multicolumn{4}{c}{ Reactivity feedback coefficient [pcm/K] } \\
Axial expansion & -0.84 & -0.85 & -0.85 \\
Radial expansion & -2.10 & -2.14 & -2.15 \\
Axial and radial expansion & -2.94 & -3.00 & -3.02 \\
Sodium density (core only) & -0.71 & -0.73 & -0.70 \\
Sodium density (all) & -1.90 & -2.02 & -1.89 \\
Uncertainty [\%] & 1.71 & 3.75 & 4.07 \\
Doppler & -0.024 & -0.023 & -0.024 \\
Uncertainty [\%] & 5.81 & 5.44 & 5.34 \\
Control rod curve & Graph & Graph & Graph \\
\hline
\end{tabular}

assemblies. For example, full-worth drivers generally have an assembly rating close to $700 \mathrm{~kW}$; half-worth drivers have one close to $400 \mathrm{~kW}$. The assembly in position 02B01 has the largest error $(66.37 \%)$ but a relatively low calculated power of $29.45 \mathrm{~kW}$. The explanation can be found in the treatment (in ERANOS) of power deposition due to neutron capture and absorption of gamma rays. The "raw" nuclear data in ERANOS contains an energy release per capture 


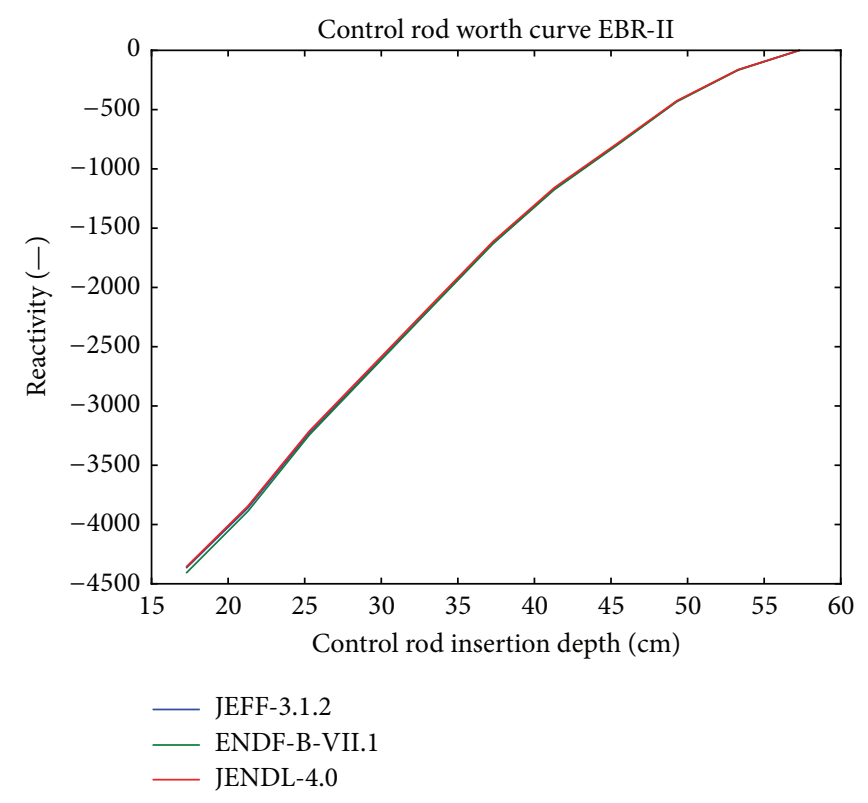

FIgURE 4: The worth curve of all control rods.

and an energy release per fission. If a reaction has secondary gamma rays, that energy is assumed to be deposited at the location of neutron capture. This is an approximation, because in reality the gamma ray will propagate through the materials and deposit its energy elsewhere.

In the present work, a somewhat improved approach was taken: the reactor power was separated into fission power and decay heat power, and subsequently it was assumed that the decay heat consists of $100 \%$ gamma rays. The energy deposition cross sections were adapted to remove any contributions due to gamma rays. For the transport of gamma rays, a separate RZ model was created and a transport theory calculation was done to determine the gamma flux and the energy deposition due to gamma rays throughout the core. Finally, the fission energy deposition was combined with the gamma energy deposition to create Figure 5. This approach seems to result in a significant overestimation of the energy deposition in nonfuel assemblies (such as the stainless steel dummies in the core).

It is possible to redo the calculations, tweaking the settings so that the errors are smaller. However, such an approach is in violation of the objectives of the present work, namely, to investigate how well the codes work "out of the box." Clearly, the transport of gamma rays and related energy deposition is a point for improvement. Finally, it should be mentioned that it is unclear whether the predicted values in the benchmark are corrected for the effects of gamma transport and gamma heating. We feel that the values presented in Figure 5 are our best estimate values and therefore these are the values we chose to present in this work.
In a recent publication [9] results of the same benchmark were published. In some cases, values reported here seem inconsistent with the values from [9]. Two aspects are noted here: the Doppler coefficient in this work $(-0.02 \mathrm{pcm} / \mathrm{K})$ is lower than that reported in [9] $(-0.05 \mathrm{pcm} / \mathrm{K})$. This is caused by the choice of the temperatures in the calculation of the Doppler effect. In this work, only the fuel temperature is increased. We performed a test calculation where the temperature of all materials is increased (including the blanket SAs), and a higher value of the Doppler coefficient was found.

The axial expansion coefficient in this work $(-0.84 \mathrm{pcm} /$ $\mathrm{K})$ is larger than that in [9] $(-0.36 \mathrm{pcm} / \mathrm{K})$. The source of this difference is difficult to judge. In any case, the magnitude of both effects is small compared to the main feedback parameters (radial expansion and coolant expansion effect).

The benchmark requires calculating the "control rod expansion effect" but without details about the control rod drive mechanisms and so forth it is difficult to make a physically realistic model. In the present work, it was chosen not to calculate this parameter. In the thermal-hydraulic calculations only the values from Table 1 were used.

\section{Thermal-Hydraulic Analysis}

The thermohydraulic analysis of the SHRT-45R experiment was performed with two codes: NETFLOW++ and RELAP5$3 \mathrm{D}$ v4.1.3. The results of the analysis with NETFLOW++ have been reported elsewhere [1] and will not be discussed here. In the NETFLOW++ code the calculation of reactivity feedback effects is not very detailed. To obtain physically reasonable results, the magnitude of the feedback parameters had to be manually adjusted. To improve our analysis, it was decided to try and use the RELAP5-3D code. Sodium is one of the working fluids available in RELAP5-3D and the code is generally applicable for the analysis of liquid metal systems. RELAP5-3D is capable of simulating 3D fluid flow, but for the present work the analysis was limited to $1 \mathrm{D}$. The main reason for this choice was that this is the general analysis method we use in our work on liquid metal fast reactors.

In the RELAP5-3D code two models to determine the power during a transient are implemented: "conventional" point kinetics and an explicit numerical solution of the time dependent neutron diffusion equation. It may seem attractive at first sight to use the explicit neutronic calculation, because it would seem that this approach gives a higher accuracy than the point kinetic model. For this benchmark, it was decided to use the point kinetic model, for the following two reasons:

(i) The point kinetic model assumes that the neutron flux shape does not change during the transient, which is a reasonable (justifiable) assumption in the present work.

(ii) To explicitly capture the effects of thermal expansion, one needs to consider the fact that the shape of the reactor changes, but the Hex-Z calculation in RELAP simply cannot take such an effect into account. One could try to use approximate methods, but then any benefit of "higher accuracy" is immediately lost. 


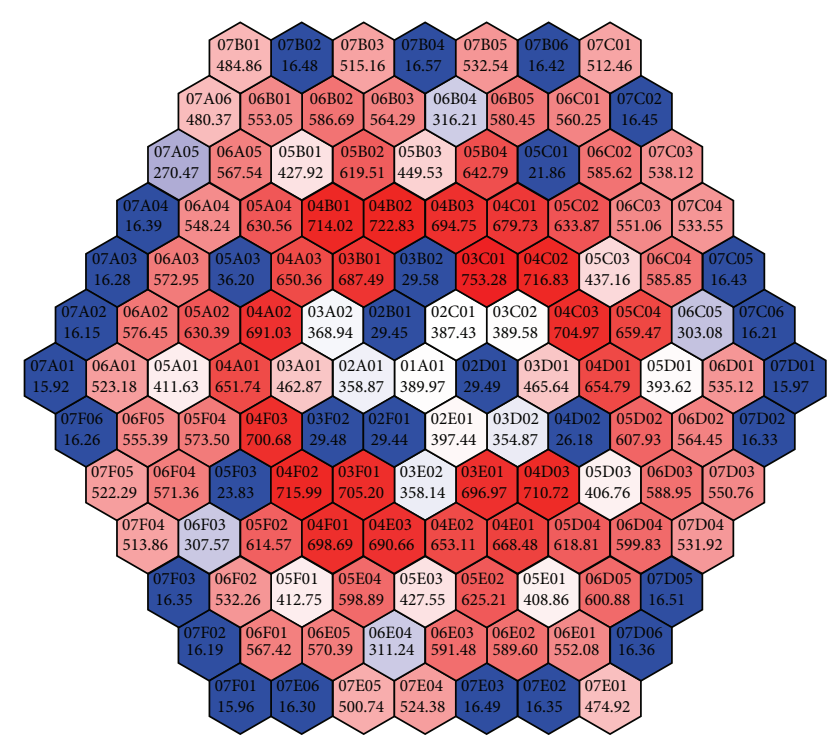

(a)

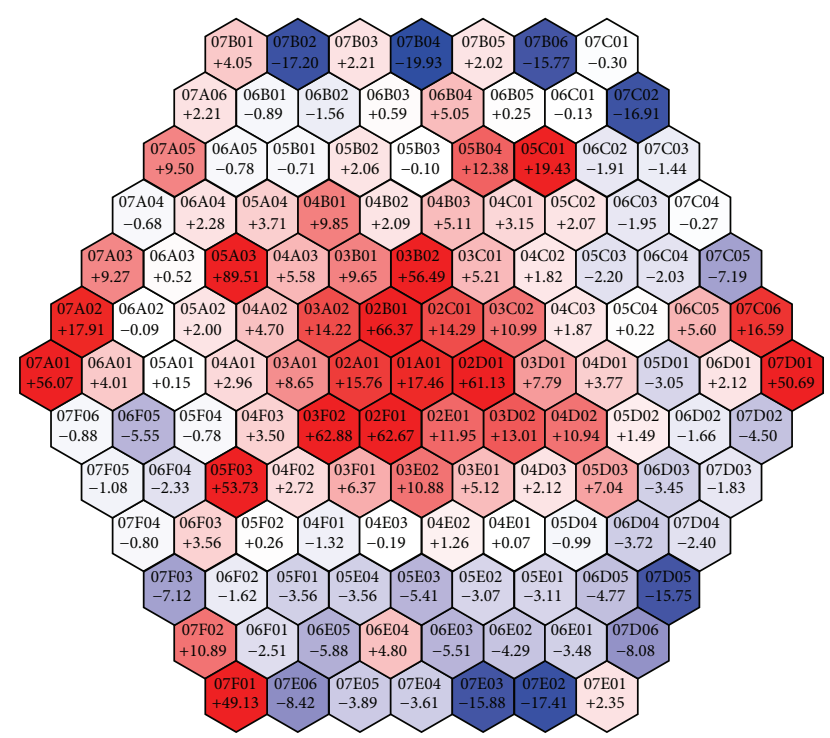

(b)

FiguRE 5: In (a) a power map for the central core region, calculated with JENDL-4.0 nuclear data. Labels: SA position, power in kW. In (b) the error in \% between the calculated assembly powers and the predicted assembly powers from the benchmark description [4]. Labels: SA position, error in \%.

It should be noted that one may attempt to capture the effects of thermal expansion directly with an RZ core model and transport theory; we have investigated such an approach, the results of which are reported in an M.S. thesis [10].

The point kinetic model requires that the user defines how the thermal-hydraulic conditions result in reactivity feedback. In other words, the user needs to define how the temperatures of the fuel, structural materials, and coolant translate into the total reactivity of the reactor. One can use "physical intuition" as well as the neutronics results to determine a reasonable distribution of feedback effects.

4.1. The RELAP Model. The EBR-II reactor is of the "tankin-tank" design, as illustrated in Figure 6. It is a "pool-loop" hybrid: loop type because there is piping from the core outlet plenum to the heat exchanger and pool type because the entire primary system and the heat exchangers are placed in one pool. According to the benchmark description, there is negligible heat exchange between the reactor vessel and the cold pool; therefore, in RELAP the primary system is treated as a loop type. The RELAP model is shown in Figure 7. There are two primary pumps, which pump the primary coolant to the inlet plenum. This inlet plenum is separated into a high pressure plenum, which takes the main part of the primary coolant flow and a low pressure plenum. The subassemblies in rows 1 to 7 of the core are connected to the high pressure plenum. A part of the coolant is diverted through two throttle valves and delivered to the low pressure plenum, to which the subassemblies in rows 8 to 16 (reflector and blanket assemblies) are connected. The coolant heats up in the core and then enters into the outlet plenum, from which there is one large pipe ("Z-pipe") going to the inlet of the intermediate heat exchanger (IHX). The outlet of the IHX discharges directly into the cold pool, from which the primary pumps take their suction. Some aspects of the thermal-hydraulic model require more explanations.

(i) Core Model. The RELAP model of the core consists of several pipes; each pipe respresents several subassemblies of a given type. The pipes are grouped as follows: assemblies are connected to the high pressure plenum (core assemblies rows 1 to 7 ) or the low pressure plenum (blanket and reflector assemblies, rows 8 to 16). For the high pressure plenum, a second distinction is made between assemblies in rows 1 to 5 (the "inner core") and assemblies in rows 6 and 7 (the "expanded core"); these last assemblies have a different design of the inlet orifices. Since the effects of thermal expansion are relevant for the feedback, detailed temperature distributions are required, and for this reason several heat structures are attached to each pipe, representing components such as the fuel, the wrapper, and the stainless steel in the lower and upper neutron shields. The relevant data (density, heat capacity, etc.) for the metallic fuel is given in the benchmark description. A total of 12 pipes are used to model the core.

(ii) Pump Model. The benchmark description does not provide homologous curves, which are required to model a pump in RELAP. Based on the information in the benchmark description about the main coolant pumps, an approximate, limited set of homologous curves was calculated and used in RELAP (see the Appendix for more details). The primary system also features an Electromagnetic Pump (EMP, also known as auxiliary pump), for which no models are available in RELAP. In the actual measurement, natural circulation was augmented by the action of the auxiliary pump (more details can be found in [4]). Since it is difficult to (arbitrarily) replace the EM pump with an equivalent, conventional pump, it was decided not to implement the EM pump as such. 


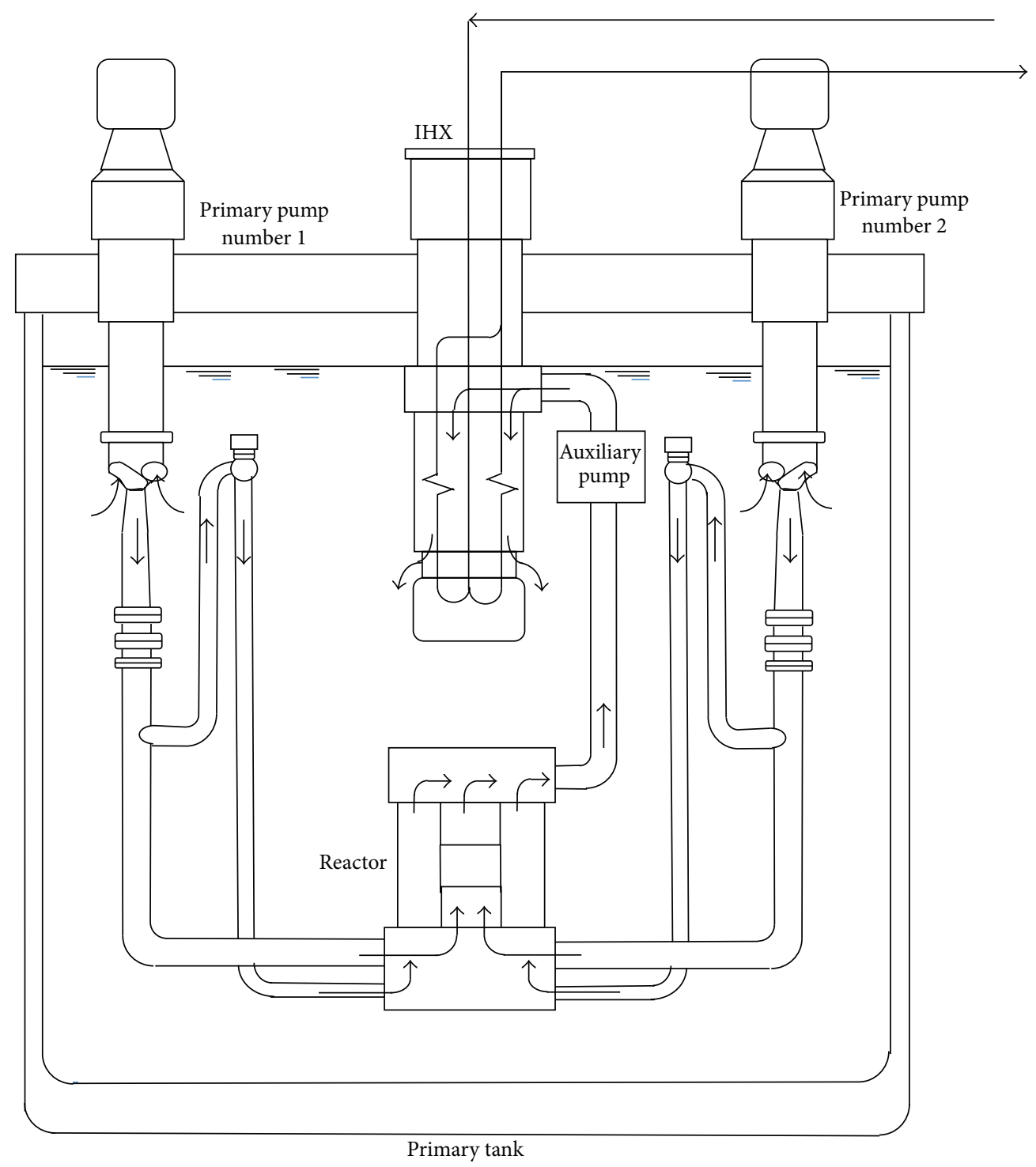

FIGURE 6: EBR-II primary system. Schematic reproduced from benchmark description [4].

Instead, the extra pump head due to the EM pump was simulated by slightly increasing the speed of the main pumps.

(iii) The Z-pipe has a double-wall structure with an inner and outer tube of stainless steel and stagnant sodium in the annular space. The $\mathrm{Z}$-pipe represents a considerable heat capacity as well as an exchange of energy between the hot sodium and the cold pool. The Z-pipe is modeled with a heat structure taking into account the double-wall structure. On the outer boundary of the Z-pipe the temperature is assumed to be constant (steady state temperature of the cold pool).

(iv) Materials. For stainless steel, the standard RELAP correlations were used. For the fuel material the correlations from the benchmark specifications were used [4]. Stagnant sodium is part of the Z-pipe, and correlations from [11] were used.
4.2. Steady State Initialization and Transient Calculation. The benchmark description does not provide a detailed description of the assembly inlet orifices, nor is there a detailed description of the throttle valves that distribute the flow between the high and low pressure plenums. Instead, a database is provided with the calculated (expected) coolant mass flow rate for each assembly in the SHRT-45R benchmark. We opted to use singular pressure drops at the inlet of each pipe through the core to set the mass flow rate correctly during steady state. As for the assembly powers, we chose to use the results from the neutronics calculations.

For the transient calculation, delayed neutron parameters obtained from the neutronic benchmark were used (JENDL4.0 ), while the decay heat was calculated with the ANS 2005 decay heat standard as available in RELAP; required 


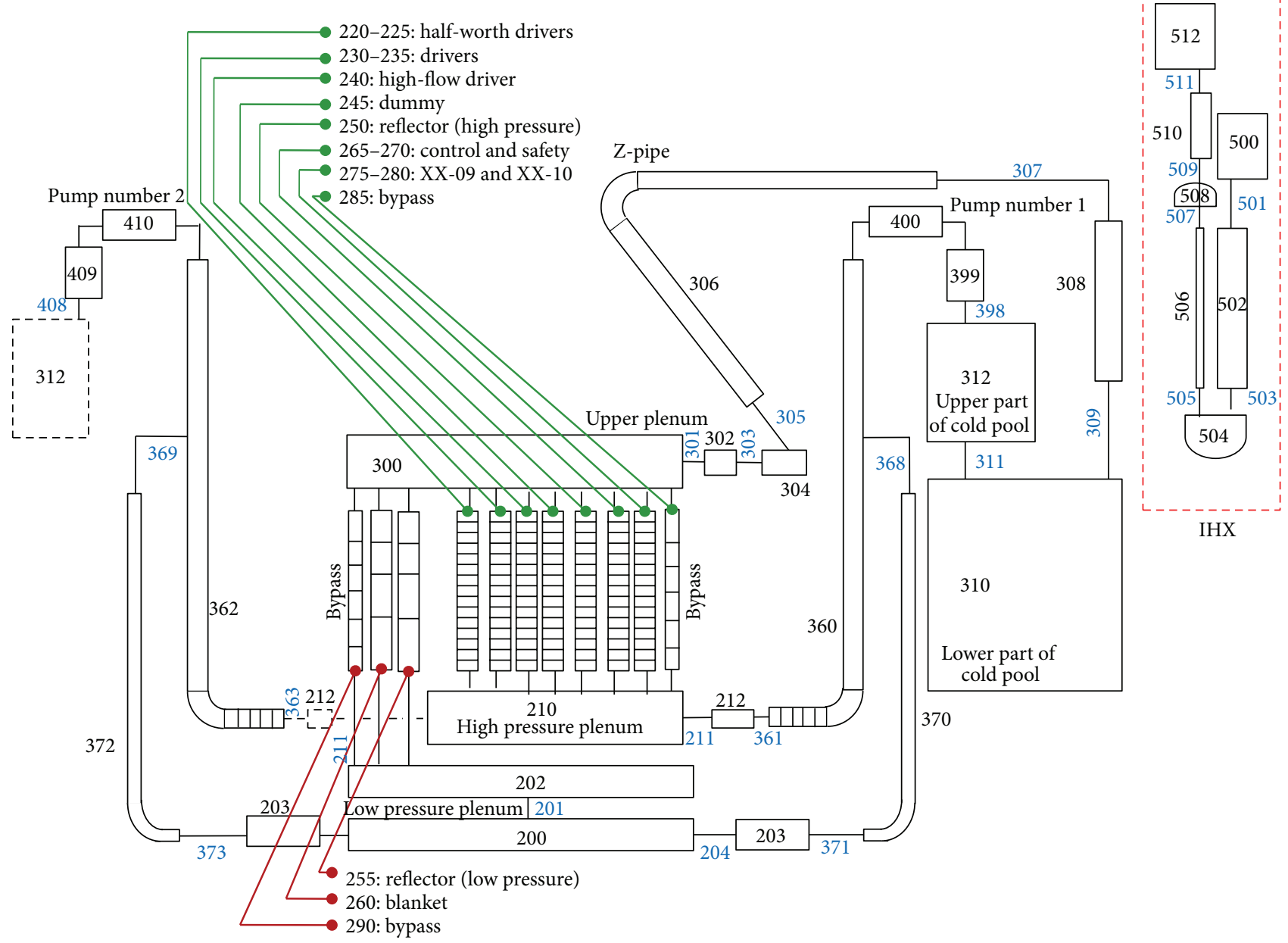

FIgURE 7: RELAP model of the EBR-II primary system. Numbers indicate pipe and junction IDs. For clarity some IDs are not printed.

input data, such as the fission rates in various isotopes, were obtained from the neutronic results. It should be noted that the ANS decay heat standards were developed for lowenriched, thermal LWR fuel and not for the highly enriched, fast-spectrum EBR fuel. In the ANS standard the decay heat due to individual isotopes is calculated, and thus only the fission rate of each isotope is important. Fission yields are not very sensitive to the neutron spectrum, and thus the decay heat from U-235 or U-238 is not very sensitive to the neutron spectrum. Since U-235, U-238, and $\mathrm{Pu}-239$ are the main fissioning isotopes in the EBR fuel (accounting for $91 \%$, $5 \%$, and $4 \%$ of the fission rate, resp.), application of the ANS decay heat standard is deemed justifiable. Optional correction factors in the ANS decay heat standard which are specific to LWRs, such as decay of activation products in the cladding and decay of TRU isotopes, were not used.

We used the "separable" feedback model in RELAP. In this model, there are two reactivity components, namely, a contribution from fuel temperature and a contribution from the coolant temperature and density. Several heat structures are associated with each cooling channel. There are heat structures representing the fuel but also the wrapper tube, the axial shields, and so forth. RELAP allows taking into account each and every heat structure in the calculation of the feedback coefficients; this feature was used to take into account the effect of the temperature of the stainless steel (and thus the thermal expansion). Feedback coefficients, especially those for thermal expansion, were obtained with "uniform" perturbations; that is, for the thermal expansion, the core materials are supposed to expand uniformly everywhere in the reactor. However, this does not mean that every part of the reactor gives the same (averaged) reactivity contribution upon thermal expansion. The neutronic investigations provide an insight into the distribution of the feedback effect.

\section{Results of the TH Benchmark}

In the following figures we provide an overview of the most important results of the ULOF transient calculation. In the graphs we illustrate our results and also measured data from the actual experiment. The measurement data was made available when the first, "blind" phase of the benchmark was over. We did our RELAP calculations after the measurement data was made available and therefore we decided to include the measurement data in our results. 
In Figure 8 the reactor power (separated into total power, fission power, and decay heat power), the reactivity, the coolant flow rate through the primary pumps and the inlet plena, the temperature of the inlet plena, and the temperature of the outlet plenum are given. Here we would like to draw attention to the following: the fission power in our calculations is consistently lower than the measured power, whereas the coolant flow rate is consistently higher than that measured during the first four minutes of the transient. At the same time, the temperature in the outlet plenum is consistently higher than the measured temperature. With our calculations (lower power, higher flow rate) one would expect that the calculated temperature in the outlet plenum would be lower than the measured temperature.

We also note that the mass flow rate in the low pressure plenum (to which the blanket assemblies and most of the reflector assemblies are connected) is consistently too high (Figure $8(d)$ ), but since the total mass flow rate is low in the low pressure plenum it would not influence the total transient to a large extent. During the first few minutes, before natural circulation sets in, the approximate pump model seems to perform adequately with an error of less than $20 \%$ during the first 4 minutes of the transient. The sudden increase in coolant flow rate at 11 minutes is due to the start of the auxiliary EM pump, which we simulated by increasing the rotational speed of the primary pumps.

In Figure 9 the outlet temperatures of the various types of assemblies are given, as far as measurement data is available. In Figures 9(a) and 9(b) there is a distinction between assemblies connected to the "inner core" (i.e., assemblies in rows 1 to 5) and assemblies connected to the "outer core" (assemblies connected to rows 6 and 7). In the inner core calculational results are in line with the measured data but for the outer core the temperature is generally overestimated. This is also true for the high-flow driver assemblies which are all connected to the outer core. The calculational results are poor for the reflector and blanket assemblies, where the trend of the calculations is opposite to that of the measured data (Figures 9(d) and 9(e)).

Finally, in Figure 10 the temperatures at the inlet of the Zpipe, the inlet of the IHX primary side, and the temperatures at the inlet and outlet of the secondary side of the IHX are given.

5.1. Discussion. Given that our calculations give a good result for the fission power, it is rather surprising that the core outlet temperatures are consistently overestimated, even if the coolant flow rate appears to be somewhat underestimated during natural convection (roughly from about 4 minutes) and even if the measured data may not always be reliable. These results require discussion:

(i) In the actual reactor, the outlet (cold side) of the IHX discharges directly into the cold pool. As a result, $3 \mathrm{D}$ effects are to be expected. In our present model, the cold pool consists of two 1D pipes, and thus the $3 \mathrm{D}$ temperature distribution cannot be calculated. Although the RELAP5-3D code is capable of 3D calculations, we chose to use the $1 \mathrm{D}$ model. A 3D CFD analysis of the cold pool has been performed (results to be published later) and it was found that results were very similar to the results from the $1 \mathrm{D}$ model.

(ii) There is a discrepancy in the temperature along the $\mathrm{Z}$-pipe. Heat loss from the Z-pipe is explicitly taken into account in our calculations. The measured temperatures seem to be unrealistically low. For example, the measured temperature difference between the Z-pipe inlet and the Z-pipe outlet (IHX primary inlet) implies a considerable heat loss along the Zpipe, which is not reproduced in our calculations. An explanation may be found by considering the locations of the thermocouples, which are not known exactly, and it is possible that things like thermal stratification play a role as well.

(iii) Similarly, for the temperature at the primary outlet of the IHX, there is a discrepancy between measurement and calculation which may be due to the location of the sensor. It appears that the temperature sensor was in the cold pool, being near the IHX outlet rather than in the outlet. Therefore, the measured temperature is basically the (rather constant) temperature of the cold pool rather than the oulet temperature of the IHX.

(iv) For the overestimation of the core outlet temperature, an explanation can be found in the flow distribution. As seen in Figure 8(d), the flow rate in the high pressure plenum is generally underpredicted. We used singular pressure drops to set the steady state flow rates in accordance with the benchmark specifications. These singular pressure drops are proportional to $(1 / 2) \rho v^{2}$. As flow rates decrease during the transient, so does the coolant velocity and as a result the impact of the singular pressure drops changes nonlinearly, and the flow distribution through the core will change. We support this suspicion with the following two observations: (1) the flow rate in the low pressure plenum, which is consistently too high during the transient (see Figure $8(d)$ ). It appears that perhaps the modeling of the throttle valves needs improvement. (2) The high pressure plenum is designed to feed high-powered inner core assemblies in rows 1 to 5 (the inner core) and blanket assemblies in rows 6 and 7 with a relatively low power. To obtain proper cooling conditions, the high pressure plenum contains a mechanism to distribute the coolant mass flow over rows 1 to 7 . For the actual SHRT-45R experiment, there were fuel assemblies in rows 6 and 7 rather than blanket assemblies. To accommodate these high powered assemblies in rows 6 and 7, these assemblies are of the "high-flow" design with an adapted inlet orifice. In the benchmark, the flow distribution system is neglected and singular pressure drops are used to distribute the steady state coolant mass flow. It appears that this leads to an underestimation of the flow (and thus an overestimation of the temperature) in the assemblies connected to rows 6 and 7 (the "outer core") during the transient. 

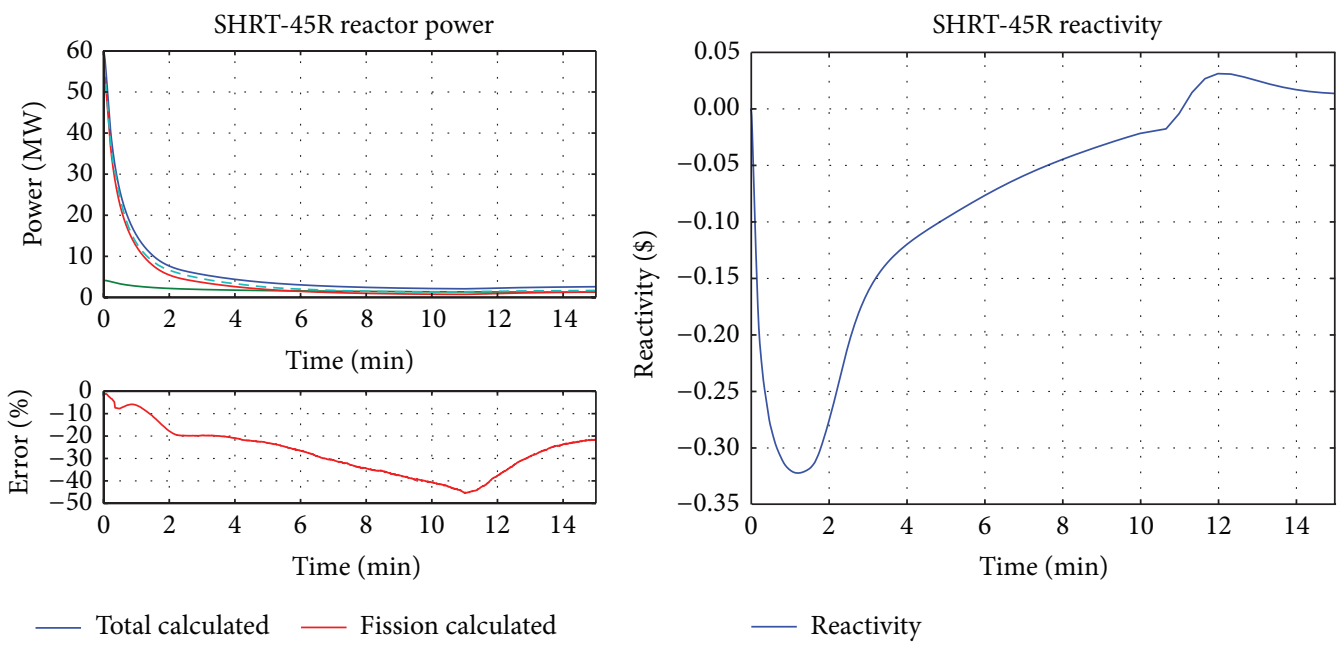

Total calculated $\quad$ Fission calculated
_ Decay calculated $\ldots$ Fission experimental (a) Power

(b) Reactivity
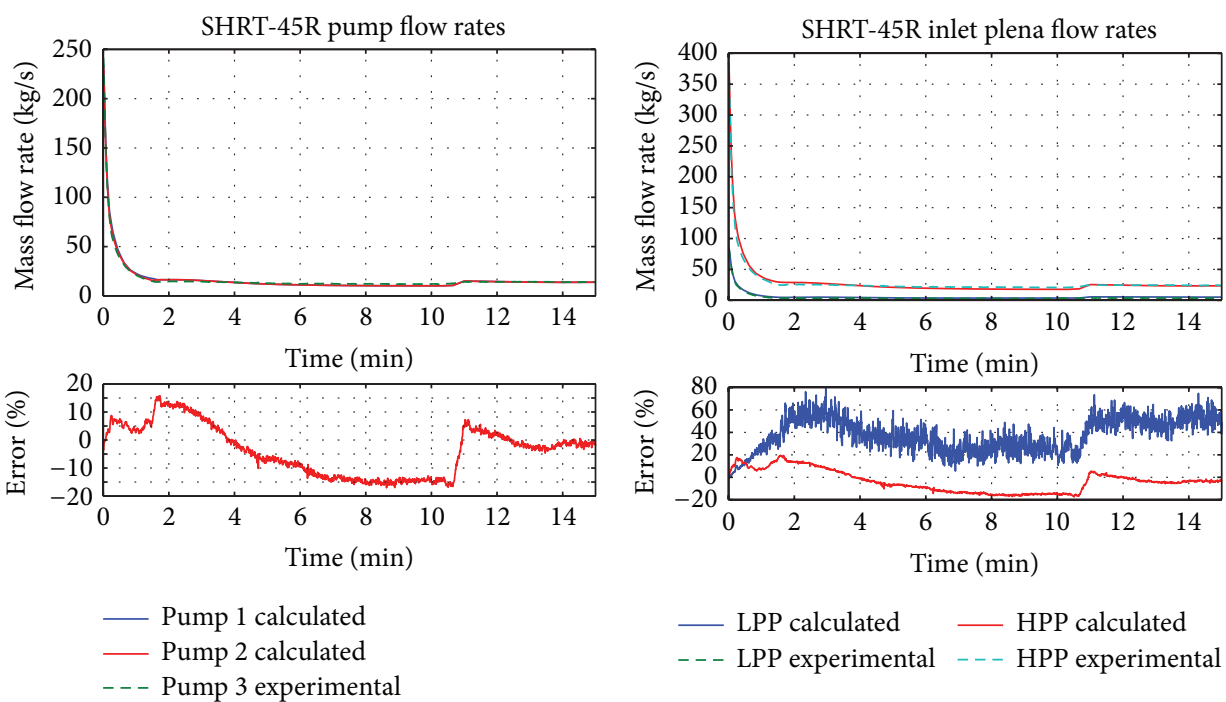

(c) Pump flow rate

(d) Inlet plena flow rate
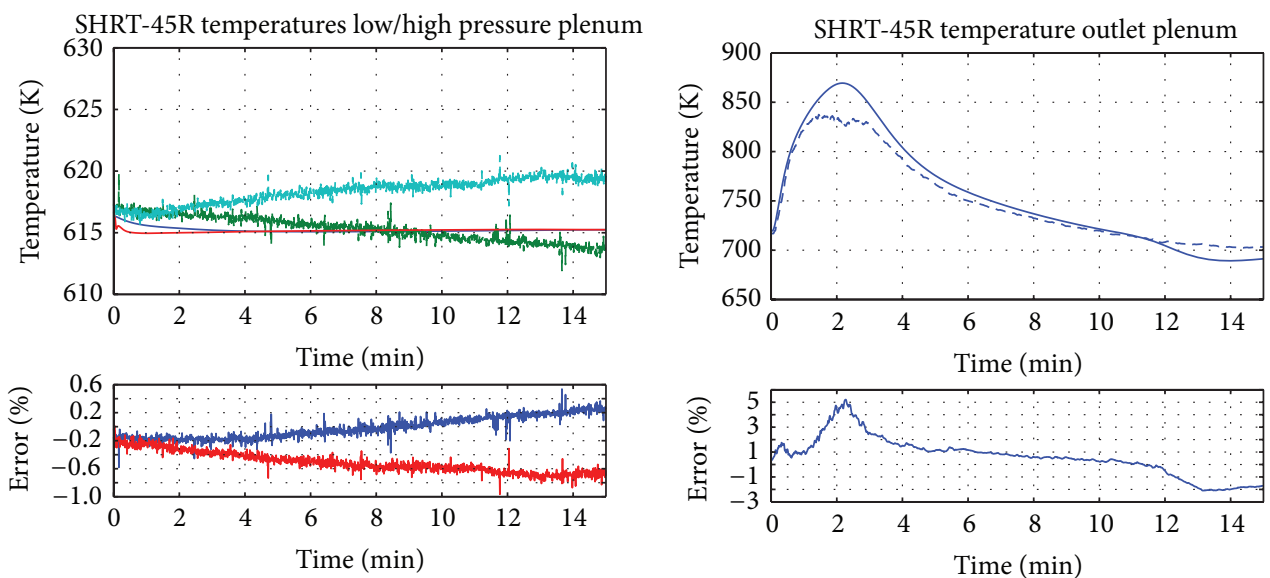

$\begin{array}{ll}\text { _ LPP calculated } & \text { HPP calculated } \\ \text { - - LPP experimental } & \text { - - HPP experimental }\end{array}$

(e) Inlet temperature

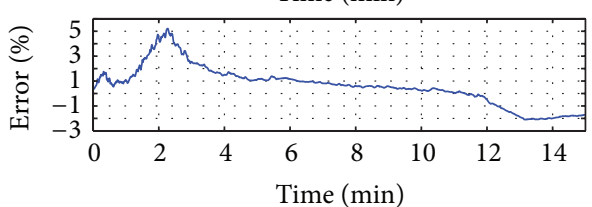

_ Outlet plenum calculated

- - Outlet plenum experimental

(f) Outlet temperature

FIgURE 8: Results of the TH benchmark. 

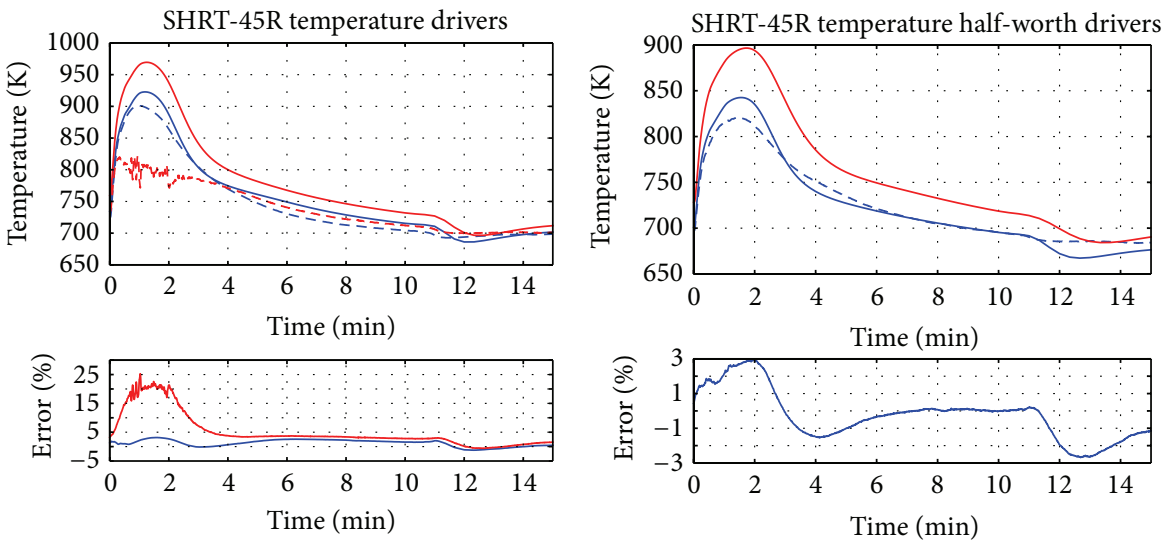

_ Driver inner calculated

- - - Driver inner experimental

_ Driver outer calculated

- - - Driver outer experimental

(a) Outlet temperature driver

SHRT-45R temperature high-flow drivers
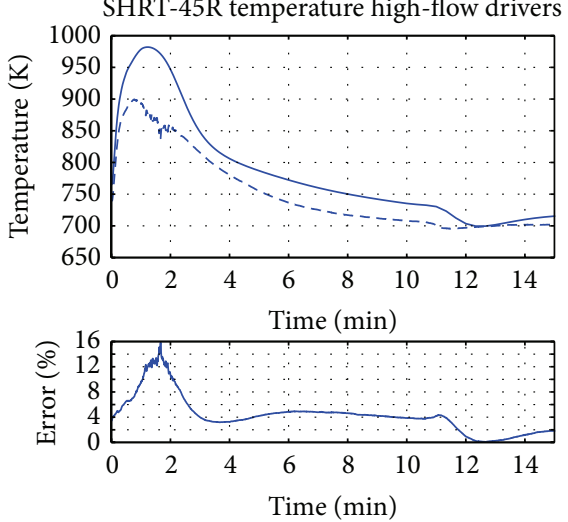

_ Half-worth inner calculated

- - - Half-worth inner experimental

— Half-worth outer calculated

(b) Outlet temperature half-worth driver
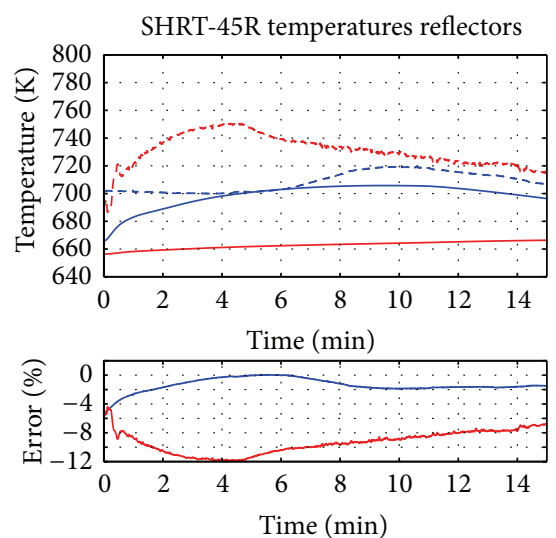

_ High-flow calculated

- - - High-flow experimental

— HPP reflector calculated

- - - HPP reflector experimental

— LPP reflector calculated

--- LPP reflector experimental

(c) Outlet temperature high-flow driver

(d) Outlet temperature reflector

SHRT-45R temperature blanket
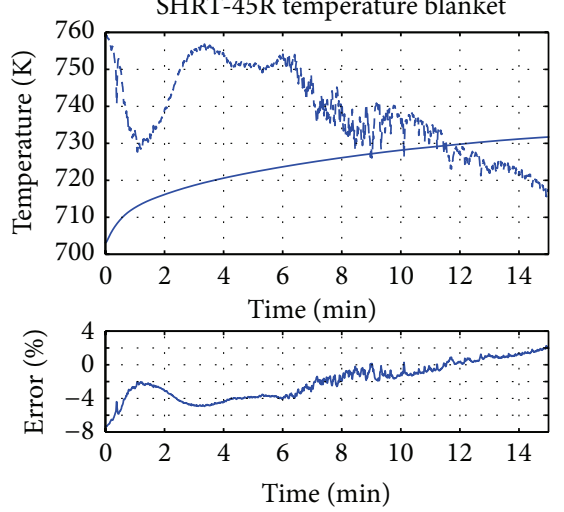

_ Blanket calculated

- - - Blanket experimental

(e) Outlet temperature blanket

FIGURE 9: Results of the TH benchmark. 

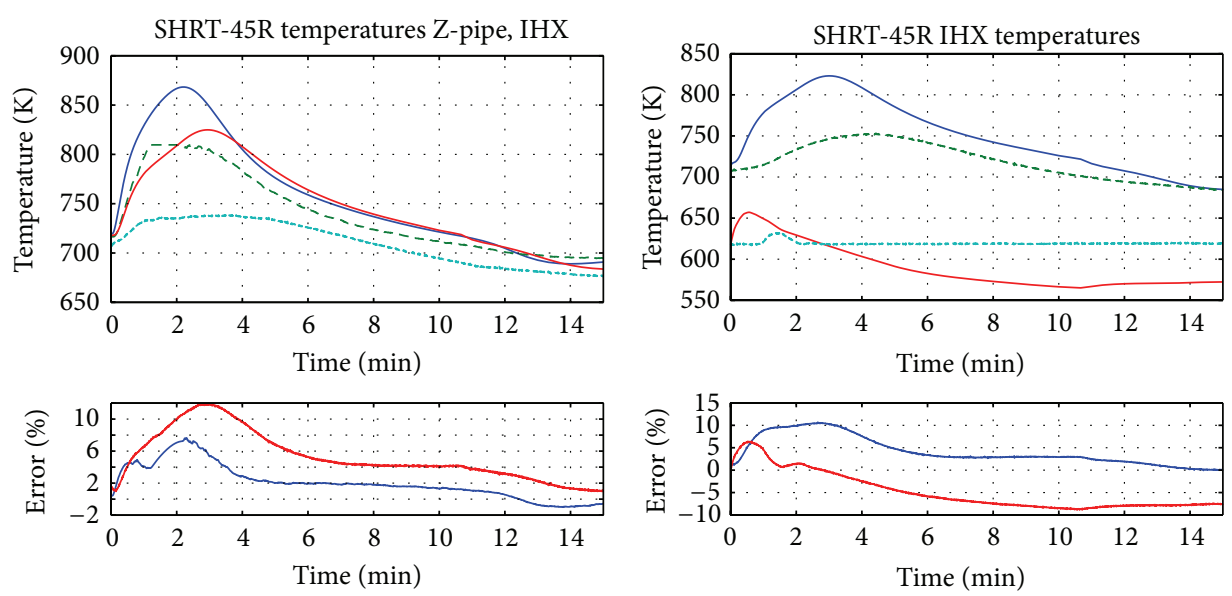

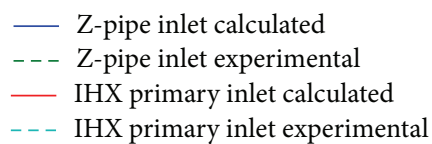

(a) Z-pipe inlet and IHX inlet temperature

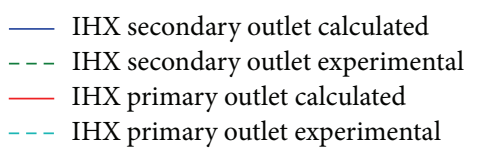

(b) IHX secondary side temperature

FIGURE 10: Results of the TH benchmark.

(v) The results for the reflector and blanket assemblies are particularly poor. These results require a more detailed explanation. First of all, measurement data is only available for one assembly position in each case (one reflector connected to the high pressure plenum, one reflector connected to the low pressure plenum, and one blanket position). Therefore, the measurement positions are not necessarily representative of the average behaviour. In RELAP, the blanket is separated into the measured SA and the 329 "average" SAs. For the measured SA, the benchmark specifies a predicted power of $26.76 \mathrm{~kW}$ (calculated value with ERANOS: $22.65 \mathrm{~kW}$ ) and a flow rate of approximately $0.16 \mathrm{~kg} \mathrm{~s}^{-1}$. This gives an expected outlet temperature on the order of $750 \mathrm{~K}$, which is consistent with the measured value of $759 \mathrm{~K}$. Our calculation (power from ERANOS) gives about $705 \mathrm{~K}$ as the initial outlet temperature. During the transient, the calculated temperature trend is opposite to the measured trend. As seen in Figure 8(d), the flow rate through the low pressure plenum is generally overestimated, and, as a result, the calculated outlet temperatures in the SAs connected to the low pressure plenum are too low.

Results might be improved if a more complete description of the assembly inlet orifices and the flow distribution device in the high pressure plenum is available as well as a detailed description of the throttle valves to the low pressure plenum; in that case, there may be less reliance on the tuning of the singular pressure drops to set the flow distribution. Another improvement would be to simulate the reflector and blanket assemblies as multiple channels, perhaps grouped on average power rating per assembly.

\section{Conclusions}

6.1. Neutronic Benchmark. We prepared a faithful model of the EBR-II reactor core during the SHRT-45R experiment. Three sets of modern, evaluated nuclear data were used and gave consistent and good results for the major neutronic parameters: multiplication factor, Doppler coefficient, thermal expansion effect, and delayed neutron fraction. The core power distribution was calculated with a separation between fission power and power deposition due to gamma rays. It appears that this modeling needs to be improved, as evidenced by the nonfuel assemblies for which the assembly powers are rather overestimated. Compared to the benchmark data, the predicted assembly powers in the core are consistent, with the exception of nonfueled assemblies.

On the whole a good result has been obtained. It should be noted that for an actual reactor the results can be improved further using techniques like cross section adjustment.

6.2. Thermal-Hydraulic Benchmark. A model of the EBR-II primary system was made with the RELAP5-3D code. This model takes into account the most important features of the benchmark description. The distribution of the coolant mass flow over the various pipes through the core was obtained with the help of singular pressure losses on the inlet orifices. Assembly powers from the neutronic benchmark were used in combination with expected flow rates from the benchmark description.

Good agreement was obtained for the steady state condition, where our results are supported by measured data from the actual experiment. During the transient, good agreement was found for the coolant mass flow rate in the pumps and fission power. The temperature in the outlet plenum is consistently overestimated, a fact which cannot be well 
explained at this time. Large discrepancies between calculation and experiment are observed for the outlet temperatures of the reflectors and blankets. These discrepancies are partly attributed to erroneous distribution of the coolant mass flow.

The RELAP code provided a detailed distribution of reactivity contributions, so that it was not necessary to "tune" the feedback coefficients to obtain a good transient behavior of the EBR-II primary system.

During the setup of the transient calculations, some imperfections were discovered in the benchmark specification. However, these imperfections would only change the results in detail, not the big picture.

\section{Appendix}

\section{Pump Model and Homologous Curves}

The benchmark documents give the following model for the EBR primary pumps:

$$
\bar{H}=b_{1} \bar{s}^{2}+b_{2} \bar{s} \bar{w}+b_{3} \frac{\bar{w}}{|\bar{w}|}|\bar{w}|^{b_{4}}
$$

with $\bar{H}=H / H_{r} ; H$ is pump head and $H_{r}$ is rated pump head; $\bar{s}=s / s_{r} ; s$ is pump speed and $s_{r}$ is rated pump speed; $\bar{w}=w / w_{r} ; w$ is coolant flow rate; and $w_{r}$ is rated coolant flow rate. The parameters $b_{1}, b_{2}, b_{3}$, and $b_{4}$ are functions of the flow conditions in the pump. RELAP requires homologous curves, so this model is not immediately applicable. For SHRT-45R, $s \geq 0$ and $w \geq 0$, and $b_{4}=1.9$ over nearly the entire operational domain of the pump. Therefore, we choose to approximate $b_{4} \approx 2$, and with $|w|=w$ (because $w \geq 0$ ) we find

$$
\bar{H}=b_{1} \bar{s}^{2}+b_{2} \bar{s} \bar{w}+b_{3} \bar{w}^{2} .
$$

Based on this last form, approximate homologous curves can be determined for $\bar{H} / s^{2}$ and $\bar{H} / w^{2}$.

\section{Conflict of Interests}

The authors declare that there is no conflict of interests regarding the publication of this paper.

\section{References}

[1] H. Mochizuki, K. Muranaka, T. Asai, and W. F. G. van Rooijen, "Benchmark analyses for EBR-II shutdown heat removal tests SHRT-17 and SHRT-45R," Nuclear Engineering and Design, vol. 275, pp. 312-321, 2014.

[2] The RELAP5-3D Code Development Team, RELAP5-3D Code Manual, vol. 1-5 of INEEL-EXT-98-00834 Revision 4.1, Idaho National Laboratory, 2013.

[3] T. Fei, A. Mohamed, and T. K. Kim, "Neutronics benchmark specifications for EBR-II shutdown heat removal test SHRT45R,” Tech. Rep. ANL-ARC-228 (rev. 1), Argonne National Laboratory, Lemont, Ill, USA, 2013.

[4] T. Sumner and T. Y. C. Wei, "Benchmark specifications and data requirements for EBR-II shutdown heat removal tests SHRT-17 and SHRT-45R," Tech. Rep. ANL-ARC-226, Argonne National Laboratory, May 2012.
[5] G. Rimpault, D. Plisson, J. Tommasi et al., "The ERANOS code and data system for fast reactor neutronic analyses," in Proceedings of the International Conference on the New Frontiers of Nuclear Technology (PHYSOR '02), Seoul, South Korea, October 2002.

[6] K. Shibata, O. Iwamoto, T. Nakagawa et al., "JENDL-4.0: a new library for nuclear science and engineering," Journal of Nuclear Science and Technology, vol. 48, no. 1, pp. 1-30, 2011.

[7] JEFF and EFF Working Groups, The JEFF Nuclear Data Library Version 3.1.2, 2012, http://www.oecd-nea.org/dbforms/ data/eva/evatapes/jeff_31/JEFF312/.

[8] M. B. Chadwick, M. Herman, P. Obložinský et al., "ENDF/BVII.1 nuclear data for science and technology: cross sections, covariances, fission product yields and decay data," Nuclear Data Sheets, vol. 112, no. 12, pp. 2887-2996, 2011.

[9] Y. Zhang and K. Mikityuk, "Validation of the serpent and TRACE codes using the SHRT-17 and SHRT-45R loss-of-flow tests performed in the EBR-II reactor," in Proceedings of the International Congress on Advances in Nuclear Power Plants (ICAPP '15), OECD/NEA, Nice, France, June 1989.

[10] J. Faubin, Multiphysics investigation of the feedback coefficients of the EBR-II sodium fast reactor [M.S. thesis], Institut National des Sciences et Techniques Nucléaires (INSTN), Saclay, France, 2014.

[11] IAEA, "Thermophysical properties of materials for nuclear engineering: a tutorial and collection of data," Tech. Rep., IAEATHPH, 2008. 


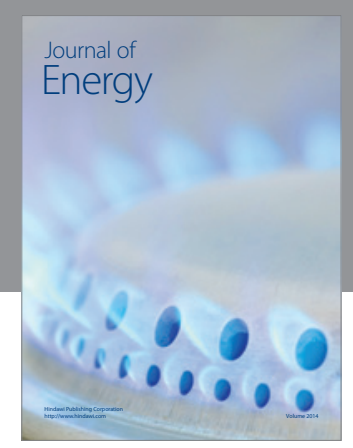

Journal of

Industrial Engineering
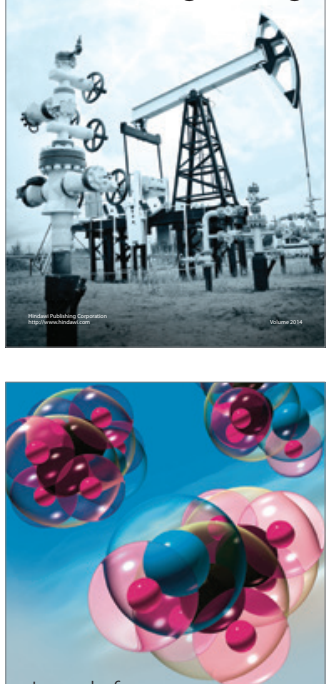

Fuels
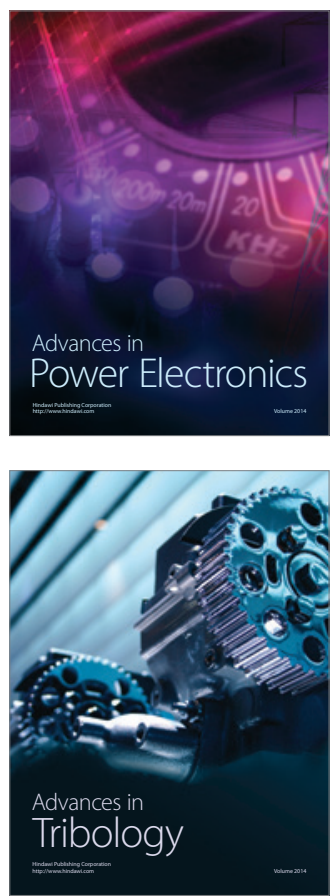

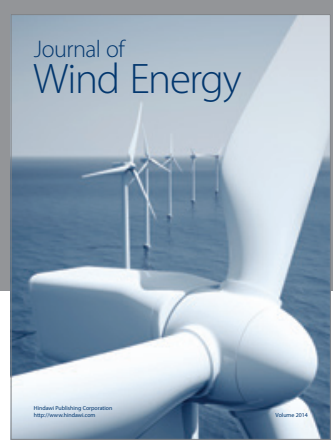

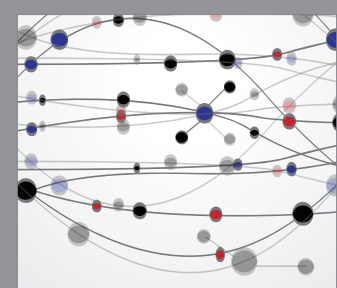

The Scientific World Journal

Submit your manuscripts at http://www.hindawi.com

Journal of

Structures
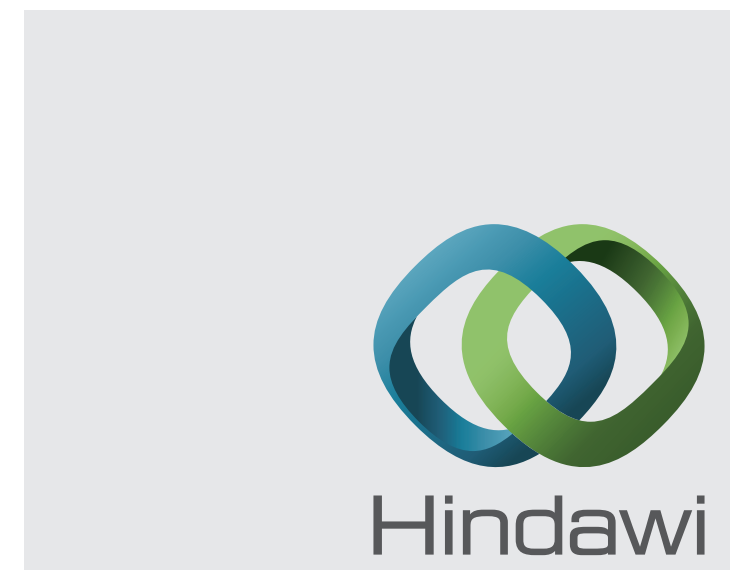

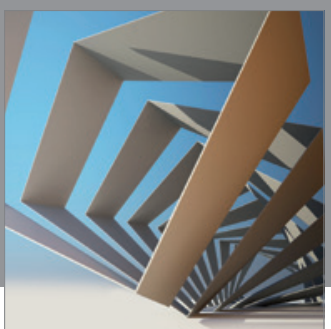

Rotating

Machinery
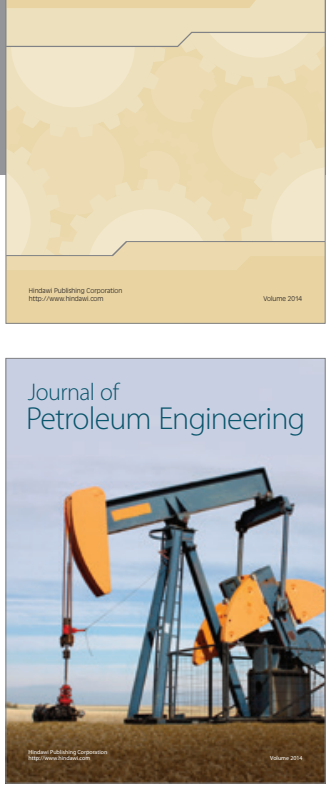

Journal of

Solar Energy
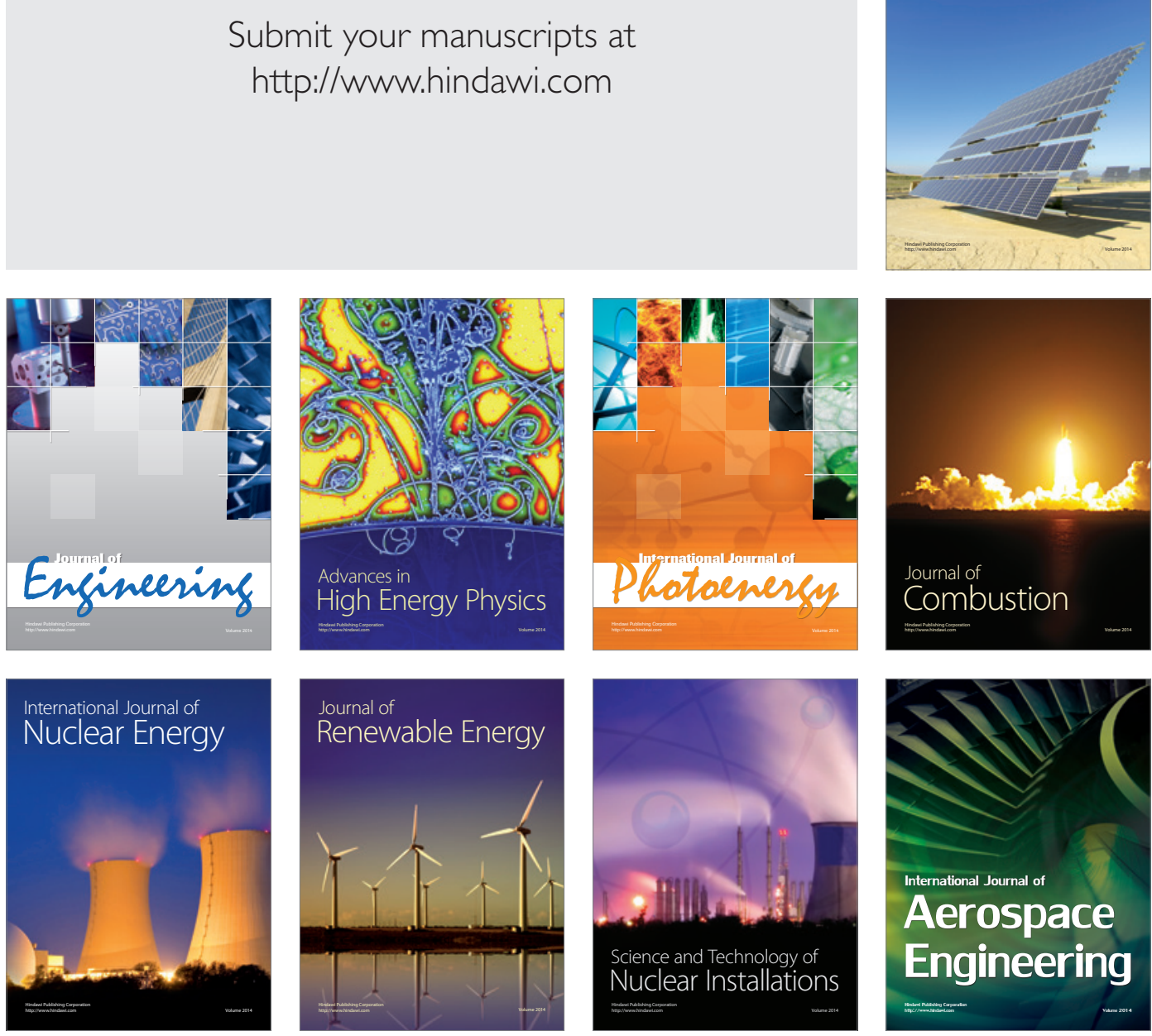